\title{
Nonlinear Companding Circuits With Thermal Compensation to Enhance Input Dynamic Range in Analog Optical Fiber Links
}

\author{
J. Rodríguez-Rodriguez ${ }^{* 1}$, J. Velazquez-Hernández ${ }^{1}$ \\ ${ }^{1}$ Instituto de Investigaciones Eléctricas, Control and Instrumentation Department \\ Reforma 113, Col. Palmira, 62490 Cuernavaca, Morelos, México \\ *jrr@iie.org.mx
}

\begin{abstract}
Measuring systems based on a pair of optical fiber transmitter-receivers are used in medium-voltage testing laboratories wherein the environment of high electromagnetic interference (EMI) is a limitation for using conventional cabling. Nonlinear compensation techniques have been used to limit the voltage range at the input of optical fiber links. However, nonlinear compensation introduces gain and linearity errors caused by thermal drift. This paper presents a method of thermal compensation for the nonlinear circuit used to improve transient signal handling capabilities in measuring system while maintaining low errors in gain and linearity caused by thermal drift.
\end{abstract}

Keywords: Nonlinear compensation, thermal compensation, optical fiber link, high power testing, input dynamic range.

\section{RESUMEN}

Los sistemas de medición basados en un par de transmisores-receptores de fibra óptica se utilizan en los laboratorios de pruebas de media tensión, en donde el ambiente de alta interferencia electromagnética (EMI) es una limitación para el uso de cableado convencional. Técnicas no lineales de compensación se han utilizado para limitar el rango de voltaje en la entrada de enlaces de fibra óptica. Sin embargo, la compensación no lineal presenta errores de ganancia y linealidad causados por la deriva térmica. Este trabajo presenta un método de compensación térmica para el circuito no lineal utilizado para mejorar las capacidades de manejo de señales transitorias en el sistema de medición, manteniendo bajos los errores en la ganancia y linealidad causados por la deriva térmica.

\section{Introduction}

Testing laboratories of High-Current and LowVoltage (HCLV) require the measure of large currents and voltages, in the order of tens of kilo amps and kilo volts. Special caution has to be applied to ensure complete electrical isolation before acquiring voltage signals and transmitting data to the control room for later processing [1]. However, the main problem is to preserve the integrity of signals which have to be transmitted without any distortion [2]. To solve this problem, a measurement system capable of measuring and carrying analog signals with a minimum added error $(1 \%)$ and with sufficient amplitude for processing had to be developed.

Optical fibers have been mainly used in digital communications applications, for which high-speed and large bandwidth are major requirements, whereas transmission of a component of direct current $(D C)$ is not necessary. On the other hand,

the accuracy and the precision of optical fiber transmission links for an analog measuring system, in high EMI conditions and other transient phenomena, is highly dependent on controlling the DC offset drift voltage due to temperature change. Consequently, it is highly desirable to devise and to implement a compensation mechanism to satisfy the measuring system requirements while handling large dynamic voltage changes. The analog fiber optic link of the measuring system is basically a fiber optic transceiver composed by three major components - the remote transmitter, the receiver unit, and the fiber optic communication link [3] (see Figure 1).

Alternatively, "companding" (from compression and expanding) is a signal processing technique primarily used in audio digital systems, such as microphones and wireless communications, to reduce noise levels. The objective of the 


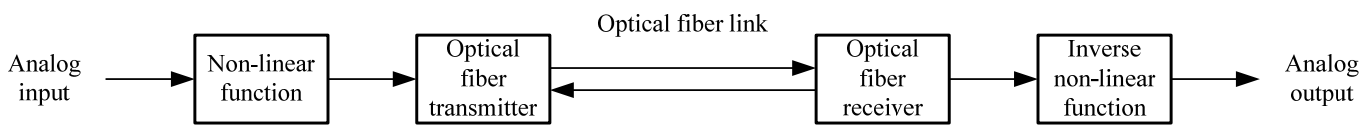

Figure 1. Analog optical fiber link block diagram.

companding process is to preserve the signal-tonoise ratio of the original audio signal. Nonlinear compensation functions are mainly used in voice communication companding. The use of companding for analog picture transmission was patented by A. B. Clark of AT\&T in 1928 [4]. Also in 1942, Clark and his team completed the secure voice transmission system, which was the first application of companding in a PCM system.[5]. Then in 1953, B. Smith showed that a nonlinear DAC could simplify the design of digital companding systems [6]. In 1965, R. Dolby in Britain developed a simple compander known as the Dolby Noise Reduction System. One of the features that set Dolby's compander apart was that it took care only of the quiet sounds that otherwise would be masked by tape noise. Dolby marketed the product to record companies. In 1970, H. Kaneko developed the uniform description of segment (piecewise linear) companding laws that have been adopted in digital telephony [7].

Digital techniques of radio over fiber (RoF) communications can be deployed with optical fibers. The measuring system in this work uses the simplest RoF method for optical transmission by Direct Intensity Modulation. This method falls under the Intensity Modulation - Direct Detection (IM-DD) technique [8]. The direct Intensity Modulation used to implement PFM optical fiber link is the method that complies with the requirement to transmit DC components. Thermal-compensation circuits in balanced semiconductor amplifiers were widely used for reducing the drift of transistorized DC amplifiers [9].

\section{Remote transmitter}

Figure 2, five modules integrate the remote transmitter: digital remote controller, analog conditioning module, nonlinear networks, analog transmitter and power supply. One fiber optic link is used to receive control commands and the other is multiplexed for control command reply and analog signal transmission.

\section{Receiver}

Figure 3 illustrates a simplified block diagram of one receiver. The analog section is in charge of detecting, amplifying and demodulating the incoming PFM signal from the transmitter module. The demodulated signal is then introduced to the inverse non-linear function network to recover the original signal from the transmitter.

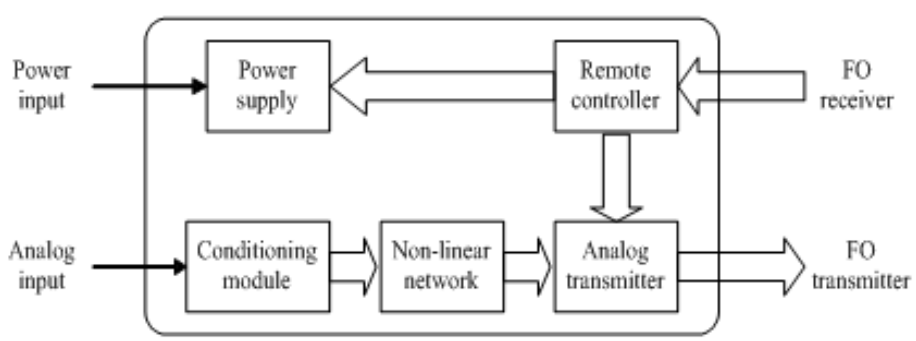

a)

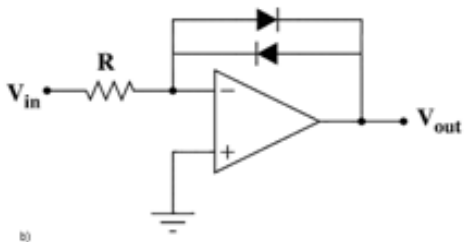

b)

Figure 2. Transmitter block diagram. b) Actual implementation for the transmitter nonlinear network. 


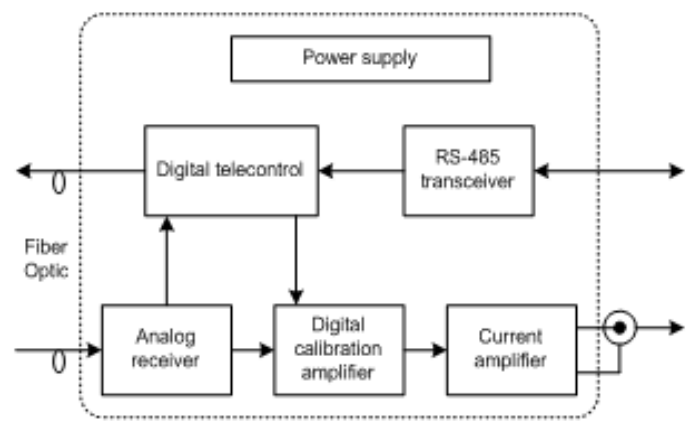

a)

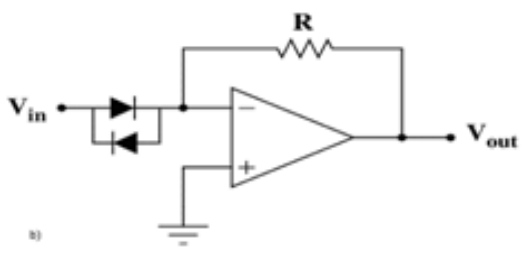

b)

Figure 3. a) Receiver block diagram. b) Implementation of the receiver nonlinear network inverse function.

\section{Companding control and thermal compensation}

Figure 4 depicts the test setup for the implementation of the companding control based on a resistance ratio. The thermal compensation of the companding network is a compromise to the companding factor. The transmitter is operating under uncontrolled temperature conditions in a test lab (ranging from 10 to $40{ }^{\circ} \mathrm{C}$ ). The receiver is operating under controlled temperature conditions in a control room in a test lab (constant $25^{\circ} \mathrm{C}$ ). The difference between input and output is the gain error that the thermal compensation reduces.
The equation of an ideal diode is

$$
I=I_{S}\left(e^{\left(V_{\mathrm{D}} / V_{\mathrm{T}}\right)}-1\right)
$$

Where $I$ is the diode current, $I_{s}$ is a scale factor called the saturation current, $V_{D}$ is the voltage across the diode, $V_{T}$ is the thermal voltage, and $n$ is the emission coefficient, also known as the ideality factor. The thermal voltage $V_{T}$ is approximately $25.85 \mathrm{mV}$ at $300 \mathrm{~K}$, a temperature close to "room temperature" commonly used in device simulation software. At any temperature, it is a known constant defined by

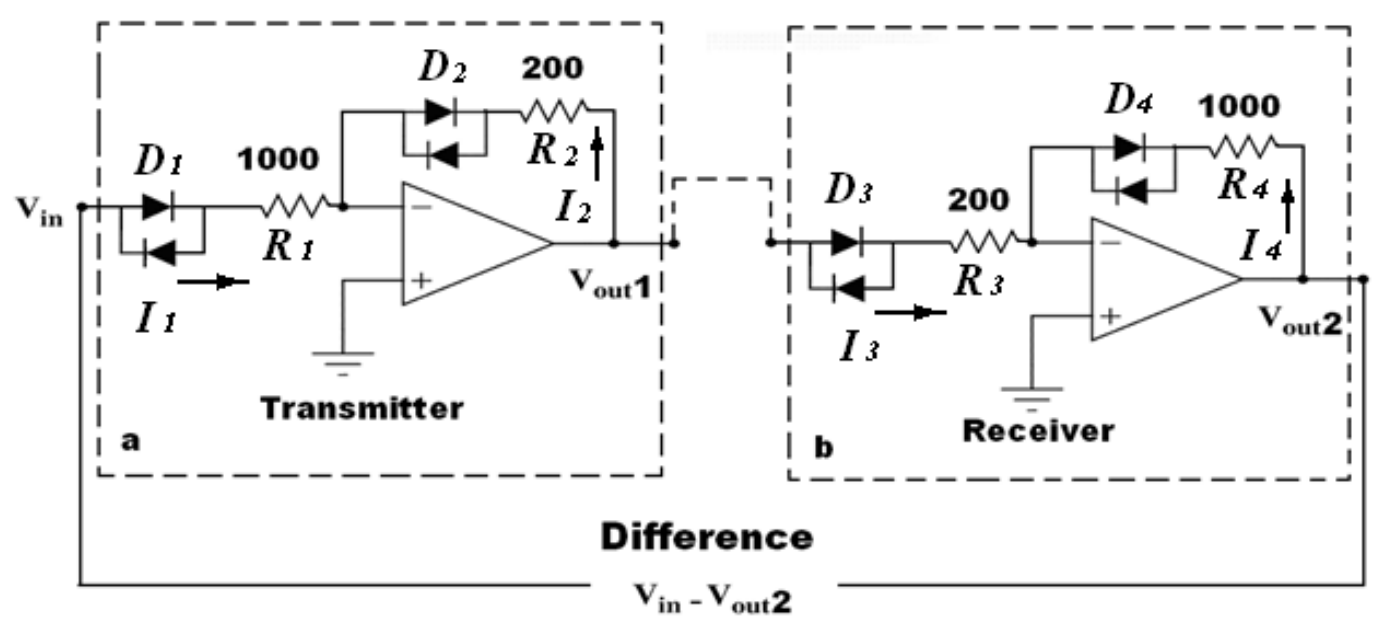

Figure 4. Test setup for the implementation of thermal compensation. a) Transmitter. b) Receiver. 


$$
V_{T}=\frac{K T}{q}
$$

Where $q$ is the magnitude of charge on an electron (the elementary charge), $K$ is the Boltzmann's constant, $T$ is the absolute temperature of the $p-n$ junction in Kelvin degrees. Under reverse bias voltages, the exponential factor in the diode equation is negligible, and the current is a constant (negative) reverse current value of $-l_{S}$. For even rather small forward bias voltages, the exponential factor is very large because the thermal voltage is very small, so the subtracted ' 1 ' in the diode equation is negligible and the forward diode current is often approximated as

$$
I=I_{S} e^{V_{\mathrm{D}} / V_{\mathrm{T}}}
$$

The current for a diode network of two diodes in parallel, one forward and one backwards, as shown in Figure 2, is

$$
I=\operatorname{sgn}\left(V_{D}\right) I_{S} e^{\left|V_{\mathrm{D}}\right| / V_{\mathrm{T}}}
$$

This diode equation is used to limit the voltage range of a bipolar signal at the output of the transmitter (input of the modulator).

The inverse function to reconstruct the shape of the original input voltage (input of the transmitter) is given by Equation (5) in terms of the transmitted voltage taken by the receiver to produce an output proportional to the original input. The output voltage for the receiver as shown in Figure 3 is

$$
V_{\text {Out }}=-\operatorname{sgn}\left(V_{\text {in }}\right) V_{\mathrm{T}} \ln \left(\left|V_{\mathrm{D}}\right| / I_{S} R\right)
$$

The non-linear circuit of the transmitter shown in Figure 4 is represented by the following equation:

$$
I_{1}=\frac{V_{i}-V_{D_{1}}}{R_{1}}=I_{2}=\frac{V_{o_{1}}-V_{D_{2}}}{R_{2}}
$$

Where $I_{1}$ is the magnitude of the input current, $I_{2}$ is the feedback current, $V_{i}$ is the input voltage, $V_{D 1}$ and $V_{D 2}$ are the diode voltage drop for $D_{1}$ and $D_{2}$, and $R_{1}$ and $R_{2}$ are the input and feedback resistances. From (6) we get

$$
V_{o_{1}}=\frac{R_{2}}{R_{1}}\left(V_{i}-V_{D_{1}}\right)+V_{D_{2}}
$$

The non-linear circuit of the receiver shown in Figure 4 can be represented by the following equation:

$$
I_{3}=\frac{V_{o_{1}}-V_{D_{3}}}{R_{3}}=I_{4}=\frac{V_{o_{2}}-V_{D_{4}}}{R_{4}}
$$

Where $I_{\mathrm{a}}$ is the magnitude of the input current, $I_{4}$ is the feedback current, $V_{1}$ is the input voltage, $V_{D 1}$ and $V_{D 4}$ are the diode voltage drop for $D_{1}$ and $D_{2}$, and $R_{3}$ and $R_{4}$ are the input and feedback resistances. From (7) we get

$$
V_{o_{2}}=\frac{R_{4}}{R_{3}}\left(V_{o_{1}}-V_{D_{3}}\right)+V_{D_{4}}
$$

By substituting (6) in (9), we get

$$
V_{o_{2}}=\left[\frac{R_{4}}{R_{3}}\left(\frac{R_{2}}{R_{1}}\left(V_{i}-V_{D_{1}}\right)+V_{D_{2}}\right)-V_{D_{3}}\right]+V_{D_{4}}
$$

By designing $R_{4}=R_{1}$ and $R_{3}=R_{2}$, we get

$$
\left(V_{o_{2}}-V_{i}\right)=\left(V_{D_{4}}-V_{D_{1}}\right)+\left[\frac{R_{1}}{R_{2}}\left(V_{D_{2}}-V_{D_{3}}\right)\right]
$$

If $\left(V_{\mathrm{D} 4}-V_{\mathrm{D} 1}\right)$ is considered equal to $\left(V_{\mathrm{D} 2}-V_{\mathrm{D} 3}\right)$ and $R_{1} \gg R_{2}$ Equation (11) can be simplified to (12):

$$
\left(V_{o_{2}}-V_{i}\right)=\frac{R_{1}}{R_{2}}\left(V_{D_{2}}-V_{D_{3}}\right)
$$

Where $\left(V_{02}-V_{\mathrm{i}}\right)$ is the voltage difference $\Delta V$ between the outputs $V_{02}$ reconstructed by the receiver and the original input $V_{i}$ at the transmitter:

$$
\Delta V=\left(V_{o_{2}}-V_{i}\right)
$$

By substituting Equation 5 in Equation 11, Equation 14 is obtained:

$$
\Delta V=\left[\frac{R_{1}}{R_{2}} \frac{K T_{1}}{q} \ln \left(\frac{\left|V_{\mathrm{i}}\right|}{I_{S} R_{1}}\right)\right]-\left[\frac{R_{1}}{R_{2}} \frac{K T_{2}}{q} \ln \left(\frac{\left|V_{\mathrm{i}}\right|}{I_{S} R_{1}}\right)\right]=\frac{R_{1}}{R_{2}}\left(\frac{K}{q} \ln \left(\left|V_{\mathrm{i}}\right| / I_{S} R_{1}\right)\left(T_{1}-T_{2}\right)\right.
$$


Equation 14 shows a linear temperature dependency compared with a simple nontemperature compensated circuit which is exponentially dependent.

Figure 5 illustrates the thermal compensated nonlinear network response. The linearity error for the transmitter, operating at $40{ }^{\circ} \mathrm{C}$, and the receiver, at $25^{\circ} \mathrm{C}$, is illustrated by the line labeled "a". The gain error for the transmitter operating at $40{ }^{\circ} \mathrm{C}$ and the receiver at $25^{\circ} \mathrm{C}$ is illustrated by the line labeled "b", and the line labeled "c" illustrates the difference between the Input and Output.

\section{Error estimation}

The errors introduced by the nonlinear companding circuits are gain, linearity and offset. The gain error is estimated through circuit simulation considering thermal dependencies of silicon diodes and considering the receiver to be at a fixed stable operating temperature of $25^{\circ} \mathrm{C}$, since the receivers are installed in a temperature-controlled environment. The transmitter, on the other hand, is installed in different locations in the HCLV lab. The gain error is the largest error introduced by the thermal dependency of the nonlinear circuit. It can be as large as $5 \%$ for $1{ }^{\circ} \mathrm{C}$ or $66 \%$ percent for 10 ${ }^{\circ} \mathrm{C}$ difference with respect to the receiver. The gain and offset errors are easily compensated by the digital signal processing routine used for calibration, as explained earlier.

A detailed response to temperature is shown in Figure 7 . The gain error introduced by the thermal dependency of the nonlinear companding is high without thermal compensation. When thermal compensation is included, the gain error is reduced in a factor of ten.

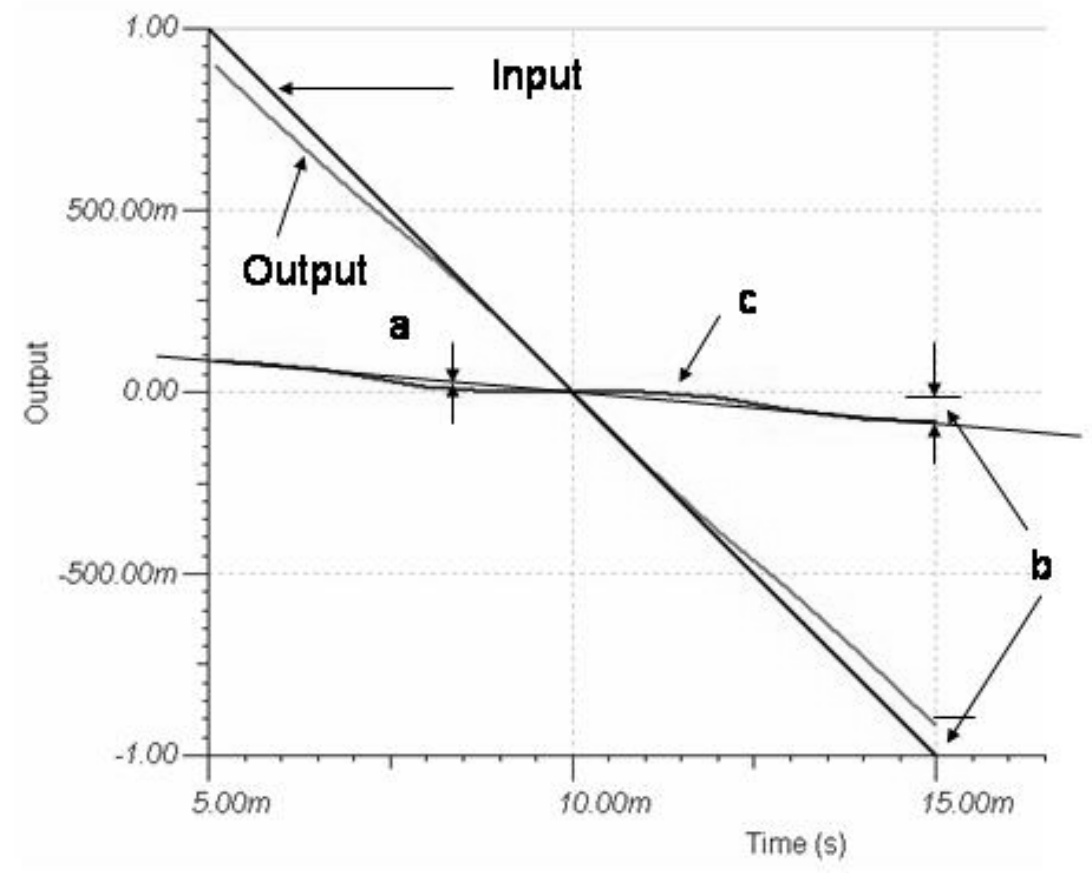

Figure 5. Thermal compensated nonlinear network response. a) Linearity error for the transmitter operating at $40^{\circ} \mathrm{C}$ and the receiver at $25^{\circ} \mathrm{C}$. b) Gain error for the transmitter operating at $40^{\circ} \mathrm{C}$ and the receiver at $25^{\circ} \mathrm{C}$. c) Difference between Input- Output. 


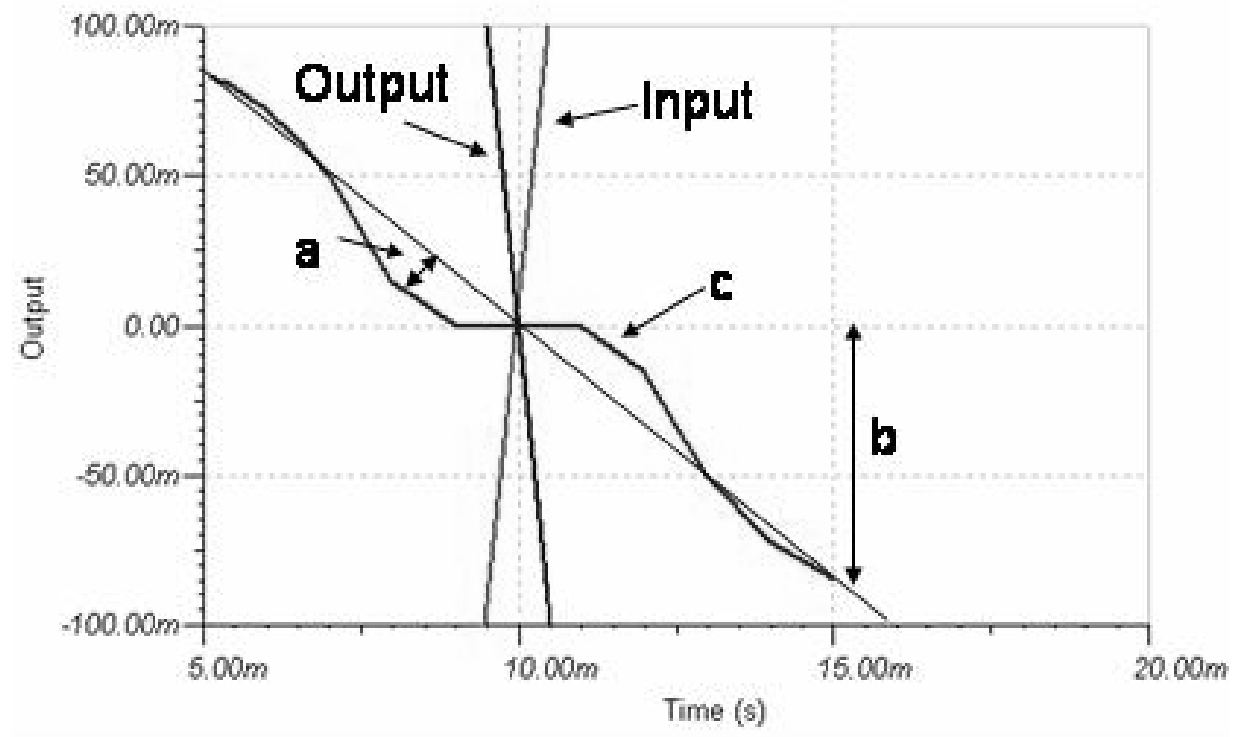

Figure 6. Zoom of thermal compensated nonlinear network response. a) Linearity error for the transmitter operating at $40 \mathrm{C}$ and the receiver at $25 \mathrm{C}$. b) Gain error for the transmitter operating at $40 \mathrm{C}$ and the receiver at 25 C. c) Difference Input- Output.

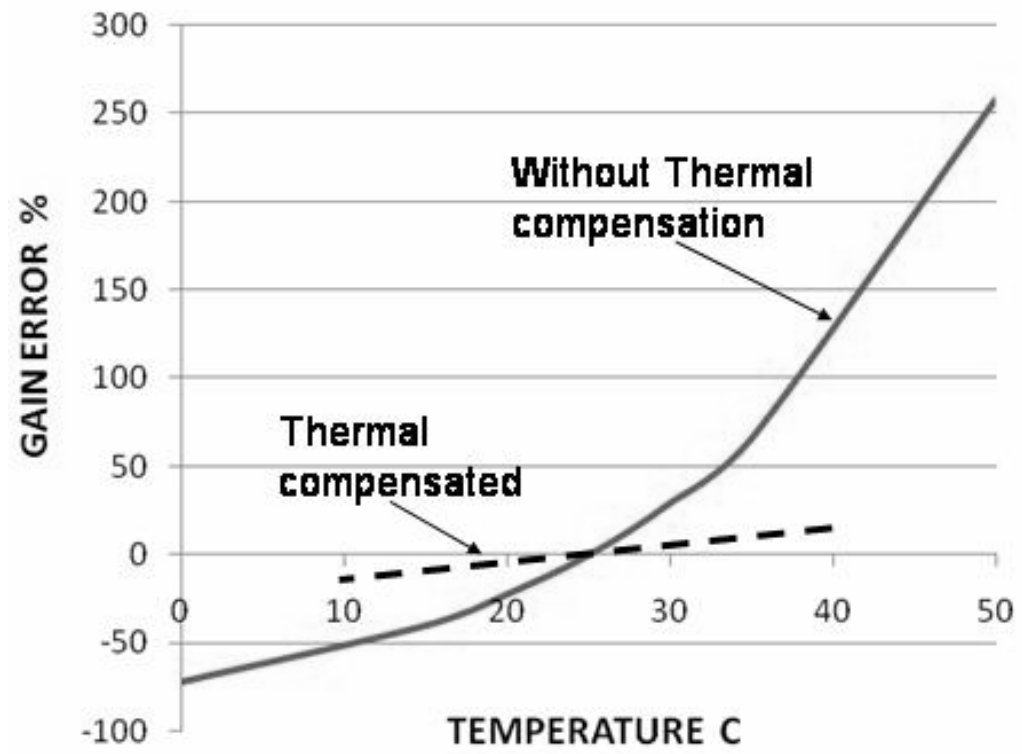

Figure 7. Gain error introduced by thermal dependency of the nonlinear companding circuits. 


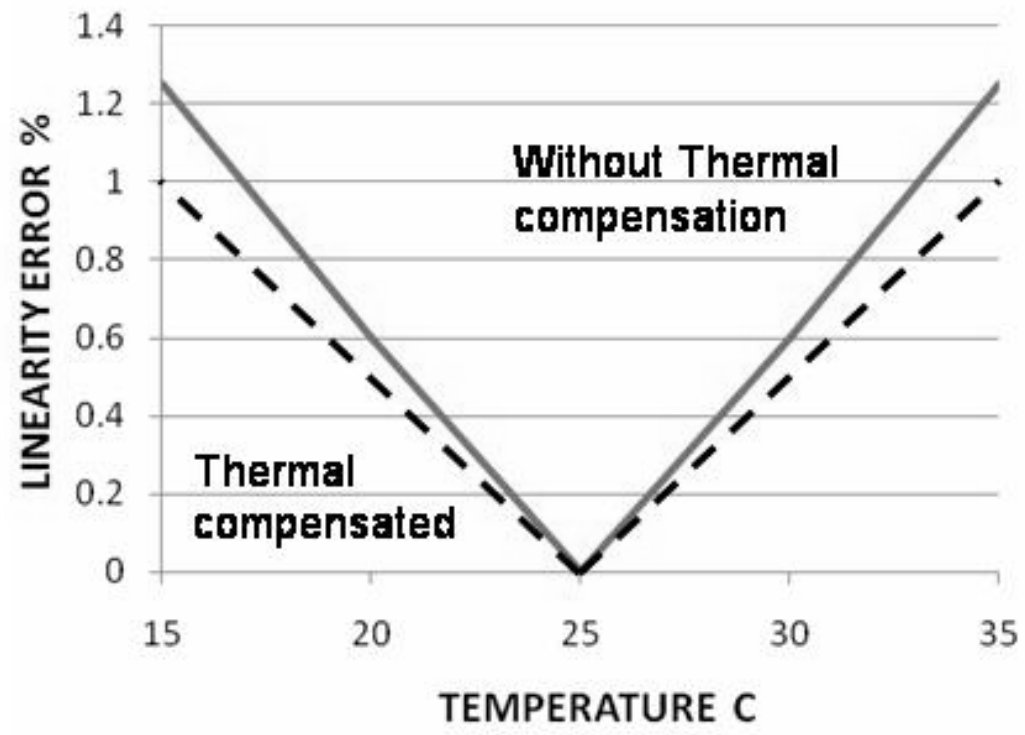

Figure 8. Nonlinearity error plot for different transmitter operating temperatures.

Simulations were performed for several temperatures above the receiver operating temperature. Figure 8 shows the linearity deviations for several temperatures. On the other hand, the nonlinearity error without thermal compensation is low. When thermal compensation is included, the nonlinearity error is not significantly reduced.

\section{Conclusions}

The thermal compensation of the nonlinear companding circuits is small compared with the error in gain introduced by a non compensated solution. It can be about $1.2 \%$ for a $10{ }^{\circ} \mathrm{C}$ difference with respect to the receiver temperature and represents a reduction in a factor of ten.

The nonlinearity error with thermal compensation is $1 \%$ and is in the same order of magnitude as a simple diode electronic circuit without thermal compensation.

This paper introduced the design and results of an improved thermally compensated nonlinear analog optical fiber link with wide input dynamic range.
Finally, the results show that non-linear network based companding improves the dynamic range of the input voltage at the transmitter and is able to reconstruct the original signal maintaining original bandwidth, low distortion, and improving signal-tonoise ratio. 


\section{References}

[1] J. Rodriguez, 2010 Application of nonlinear compensation to limit input dynamic range in analog optical fiber links, Journal of Applied Research and Technology Volume 8 no. 2 211-226

[2] Joaquin Rodriguez, 2010, Nonlinear compensation to enhance the input dynamic range in analog optical fiber links for the high current short circuit test, Measurement Science and Technology. 21 (2010) Volume 21, Number 6

[3] Velazquez J, Montero J, Rodriguez J and Garduno R 2007 Improved Analog Optical Fiber Link for Signal Measuring in a High Power Testing Facility International Journal of Mathematics and Computers in Simulation 1 40-45.

[4] Clark A B 1928 Electrical picture-transmitting system US Patent No. 1,691,147.

[5] Nichols R K and Lekkas P C 2002 Wireless Security: Models, Threats, and Solutions (New York: McGraw-Hill).

[6] Smith B 1957 Instantaneous Companding of Quantized Signals Bell System Technical Journal 36653.

[7] H. Kaneko, "A Unified Formulation of Segment Companding Laws and Synthesis of Codecs and Digital Compandors," Bell System Technical Journal, Vol. 49, September 1970, pp. 1555-1558.

[8] Ng'oma A., 2005 Radio-over-fiber technology for broad-band wireless communication systems, PhD Thesis, Dept. Telecommunications and Electronic Engineering, Eindhoven Univ. of Technology, Eindhoven, The Netherlands.

[9] V. I. Didenko., 1967. Thermal-compensation circuit in balanced semiconductor amplifiers with independent zero and temperature-balanced adjustments. Izmeritel'naya Tekhnika, No. 8, p. 91. 


\section{Authors' Biographies}

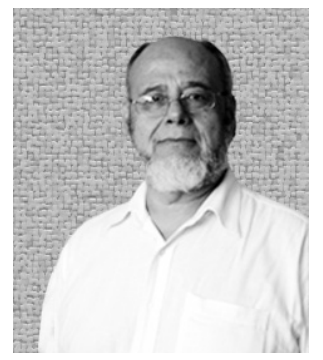

\section{Joaquin H. RODRIGUEZ-RODRIGUEZ}

Joaquin $\mathrm{H}$. Rodriguez-Rodriguez graduated as a mechanical and electrical engineer from Universidad Autónoma de Nuevo León (Autonomous University of Nuevo León) in Monterrey, Mexico in 1974, and obtained a Masters of Science degree in electrical engineering from the University of Toronto, Canada in 1980. As part of his professional experience, he worked as a research engineer for Trench Electric Ltd. of Toronto, Canada from 1979 to 1981. He joined the Instituto de Investigación Eléctrica (Electrical Research Institute) in Mexico as a researcher and head of the telecommunications laboratory, where he developed projects related to electronics, optical fibers and telecommunications systems for the electrical utilities in Mexico from 1982 to 1988. In the last four years, he has been working on MEMS Applications and optical fiber sensors for on-line monitoring of power electric apparatus. He was a professor at Instituto Tecnológico de Estudios Superiores de Monterrey (Technological Institute of Higher Education of Monterrey), ITESM, Universidad Autónoma del Estado de Morelos (Autonomous University of Morelos), and Centro de Investigación y Desarrollo Tecnológico (Center for Research and Technological Development), all in Mexico. Mr. Rodriguez has published many technical papers and participated in national and international technical meetings. From 1985 to 2007, he was recognized as National Researcher in Mexico by the Sistema Nacional de Investigadores (National System of Researchers), SNI.

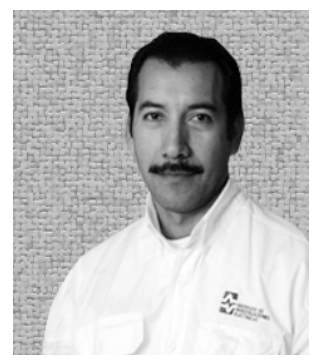

\section{Jose C. VELAZQUEZ}

Jose C. Velazquez obtained a Bachelor of Science degree in electronics engineering from the Instituto de Tecnología de Orizaba (Orizaba Institute of Technology), Mexico, and a Master of Science degree in digital systems from the Instituto Politécnico Nacional (National Polytechnic Institute), Mexico. He has been a researcher and project manager in the Departamento de Control e Instrumentación (Control and Instrumentation Department) at the Instituto de Investigación Eléctrica (Electrical Research Institute) since 1992. His research interests are digital communications and interoperability of digital communication systems. He has been responsible for many research projects with the electrical industry of Mexico. He is currently working on the modernization project of the high power tests laboratory of the Mexican national electric company. He has been a member of the Sistema Nacional de Investigadores since 2009. 